\title{
Standard-curve competitive RT-PCR quantification of myogenic regulatory factors in chicken embryos
}

L.E. Alvares ${ }^{1}$, A. Mantoani ${ }^{1}$, J.E. Corrente ${ }^{2}$ and L.L. Coutinho ${ }^{1}$
Departamentos de ${ }^{1}$ Produção Animal and

"Matemática e Estatística, Escola Superior de Agricultura "Luiz de Queiroz", Universidade de São Paulo, Piracicaba, SP, Brasil

\section{Correspondence \\ L.L. Coutinho \\ Departamento de Produção Animal \\ ESALQ, USP \\ 13418-900 Piracicaba, SP \\ Brasil \\ Fax: +55-19-3429-4285 \\ E-mail: Ilcoutin@carpa.ciagri.usp}

Research supported by FAPESP (Nos. 96/12196-0 and 2000/12864-7) and CNPq (No. 52/600197-9).

Received July 4, 2002 Accepted September 19, 2003

\begin{abstract}
The reverse transcription-polymerase chain reaction (RT-PCR) is the most sensitive method used to evaluate gene expression. Although many advances have been made since quantitative RT-PCR was first described, few reports deal with the mathematical bases of this technique. The aim of the present study was to develop and standardize a competitive PCR method using standard-curves to quantify transcripts of the myogenic regulatory factors MyoD, Myf-5, Myogenin and MRF4 in chicken embryos. Competitor cDNA molecules were constructed for each gene under study using deletion primers, which were designed to maintain the anchorage sites for the primers used to amplify target cDNAs. Standard-curves were prepared by co-amplification of different amounts of target cDNA with a constant amount of competitor. The content of specific mRNAs in embryo cDNAs was determined after PCR with a known amount of competitor and comparison to standard-curves. Transcripts of the housekeeping $\beta$-actin gene were measured to normalize the results. As predicted by the model, most of the standard-curves showed a slope close to 1 , while intercepts varied depending on the relative efficiency of competitor amplification. The sensitivity of the RT-PCR method permitted the detection of as few as $60 \mathrm{MyoD} / \mathrm{Myf}-5$ molecules per reaction but approximately 600 molecules of MRF4/Myogenin mRNAS were necessary to produce a measurable signal. A coefficient of variation of 6 to $19 \%$ was estimated for the different genes analyzed (6 to 9 repetitions). The competitive RT-PCR assay described here is sensitive, precise and allows quantification of up to 9 transcripts from a single cDNA sample.
\end{abstract}

\section{Introduction}

The combination of reverse transcription and the polymerase chain reaction (RT-PCR) has produced the most sensitive technique available to study gene expression. Under
Key words

- Quantitative RT-PCR

- Standard-curve

- Myogenic regulatory factors

- Gene expression ideal conditions, a single copy of a specific mRNA can be detected in a heterogeneous cDNA sample $(1,2)$. In addition to sensitivity, this method also has other advantages such as high specificity, tolerance to partially degraded RNAs, ability to measure 
multiple mRNAs in single samples, and potential for rapid analysis of a large number of samples (3). Because of these characteristics, RT-PCR has been widely applied in gene expression analysis, proving to be particularly useful when starting material or mRNAs are limited (4-7). Nevertheless, quantification of gene activity using RTPCR is not trivial because of the exponential nature of PCR. Even slight variations in amplification efficiency of samples containing the same number of a specific target may result in large differences in the amount of amplicons synthesized, precluding correct quantification (8).

The first applications of RT-PCR to quantify gene expression were based on the use of an endogenous control, normally housekeeping genes such as those coding for $\beta$-actin, glyceraldehyde-3-phosphate dehydrogenase or ribosomal proteins, which are assumed to be invariable among samples (9-12). The relative content of a specific transcript is obtained after results are normalized with respect to the endogenous control. This method requires amplification efficiency and abundance of control and target templates to be similar so that the exponential range of amplification of both products overlaps, allowing quantification before the plateau. Subsequently, Wang et al. (13), BeckerAndre and Hahlbrock (14) and Gilliland et al. (8) described competitive RT-PCR, which resulted in a great improvement in quantitative RT-PCR assays, allowing absolute mRNA quantification. Competitive RT-PCR uses an exogenous RNA or DNA control (competitor) that is co-amplified with the target molecule. The competitor must share identical primer binding sites with the target template but must differ in size or restriction sites to allow these fragments to be separated after PCR. Since the region to which primers bind is common, competitor and target DNA compete equally for the limiting reaction components (nucleotides, primers, enzyme). Consequently, the ratio between the two prod- ucts is kept constant throughout the reaction. The most recent version of quantitative RTPCR is the real-time RT-PCR which has simplified quantitative assays monitoring the PCR kinetics at each cycle with the use of fluorescent dyes or primers in the reaction $(2,15,16)$. However, many laboratories still do not have access to this technology due to the cost of the equipment.

Myogenic regulatory factors $(M R F s)$ are master regulators of myogenesis (reviewed in Refs. 17-19). Although they have been the subject of intense investigations, there is little information about their threshold for biological activity, magnitude of expression, and relative content during different phases of myogenesis. In this paper we describe competitive RT-PCR assays developed to quantify transcripts of the four MRFs (MyoD, Myf-5, Myogenin and MRF4) in whole chicken embryos. The theoretical requirements for the use of standard-curves in competitive RT-PCR assays are addressed for the first time. Using the classical mathematical model for competitive PCR, we determined the relative efficiency of competitors based on equations obtained from standardcurves.

\section{Material and Methods}

\section{Embryos}

Fertilized eggs from the AgRoss line were obtained from the Ninho Verde Poultry Farm (Tietê, SP, Brazil) and incubated in a humidified atmosphere at $38^{\circ} \mathrm{C}$. Embryos were staged according to Hamburger and Hamilton (20).

\section{Isolation of total RNA}

Total RNA was extracted with Trizol reagent, following manufacturer instructions (Life Technologies, Inc., Carlsbad, CA, USA). Samples were dissolved in RNase-free water and quantified by the average of duplicate 
spectrophotometric readings at $260 \mathrm{~nm}\left(\mathrm{~A}_{260}\right)$. Purity of total RNA was determined by the $\mathrm{A}_{260} / \mathrm{A}_{280}$ ratio. Before cDNA synthesis, the integrity of each RNA sample was confirmed by electrophoresis on $1 \%$ agarose gels.

\section{Single-strand cDNA synthesis}

One microgram of total RNA was reverse transcribed using an oligo $\mathrm{dT}_{12-18}(500$ ng) primer. The final reaction volume was $20 \mu \mathrm{l}$, containing $1 \mathrm{X}$ RT buffer $(20 \mathrm{mM}$ Tris$\mathrm{HCl}, \mathrm{pH} 8.4,50 \mathrm{mM} \mathrm{KCl}), 5 \mathrm{mM} \mathrm{MgCl} 2,10$ $\mathrm{mM}$ dithiothreitol, $500 \mu \mathrm{M}$ of each dNTP, $40 \mathrm{U}$ of RNaseOUT ${ }^{\mathrm{TM}}$ (Life Technologies) and $200 \mathrm{U}$ of SuperScript II RNAse H Reverse Transcriptase (Life Technologies). cDNAs were synthesized at $42^{\circ} \mathrm{C}$ for $50 \mathrm{~min}$ following inactivation of SuperScript II by heating at $70^{\circ} \mathrm{C}$ for $15 \mathrm{~min}$. To remove template mRNAs, samples were treated with $1 \mathrm{U}$ of RNase $\mathrm{H}$ at $37^{\circ} \mathrm{C}$ for $30 \mathrm{~min}$.

\section{Synthesis of target and competitor templates}

In order to construct standard-curves, tar- get and competitor cDNA templates were prepared for each gene. To synthesize the target molecules, one-tenth of the RT reaction was amplified with the specific primers listed in Table 1. These fragments were identical in size and nucleotide sequence to the cDNA obtained by RT-PCR of embryos. Competitor templates were produced by mutational PCR with the sense and antisense deletion primers (Table 1), using the corresponding target fragment as a template. The deletion primers were composed of 19 bases complementary to an internal region of the target template in addition to 20 bases identical to the antisense primer. As can be observed in Figure 1A, after PCR the region downstream to the deletion primer site was eliminated in the competitor, resulting in a slightly smaller fragment. However, since the deletion primer contains the complete sequence of the antisense primer site, this stretch is rescued on the copied fragment. Consequently, the same primer pair can be employed to amplify both target and competitor cDNAs. A schematic representation of the target and competitor cDNAs con-

\begin{tabular}{|c|c|c|c|c|}
\hline Gene & Direction & Sequences $5^{\prime}$ to $3^{\prime}$ & Nucleotide position & $\begin{array}{c}\text { GeneBank } \\
\text { acc. No. }\end{array}$ \\
\hline${ }^{a} M y o D$ & $\begin{array}{l}\text { Sense } \\
\text { Antisense } \\
\text { Antisense deletion }\end{array}$ & $\begin{array}{l}\text { TAC CCA GTG CTG GAG CAC TA } \\
\text { GTC TTG GAG CTT GGC TGA AC } \\
\text { GTC TTG GAG CTT GGC TGA ACT GGT AGA TTG GAT TGC TGC }\end{array}$ & $\begin{array}{l}641 \text { to } 660 \\
1092 \text { to } 1111 \\
1092 \text { to } 1111 \text { and } 1023 \text { to } 1041\end{array}$ & X16189 \\
\hline bMyf-5 & $\begin{array}{l}\text { Sense } \\
\text { Antisense } \\
\text { Antisense deletion }\end{array}$ & $\begin{array}{l}\text { TCC AGC TGC TCC GAT GTG AT } \\
\text { TCA TAG CGC CTG GTA GGT CC } \\
\text { ICA TAG CGC CTG GTA GGT CCG CAG CCC CGG CTC CTC CGC }\end{array}$ & $\begin{array}{l}618 \text { to } 637 \\
1302 \text { to } 1321 \\
1302 \text { to } 1321 \text { and } 1202 \text { to } 1220\end{array}$ & $X 73250$ \\
\hline${ }^{\mathrm{C} M R F 4}$ & $\begin{array}{l}\text { Sense } \\
\text { Antisense } \\
\text { Antisense deletion }\end{array}$ & $\begin{array}{l}\text { AGG CTG GAT CAG CAG GAC AA } \\
\text { CTC ATT TCT CCA CCG CCT CT } \\
\text { CTC ATT TCT CCA CCG CCT CTT GCT GTC CAC GAT GGA GGA }\end{array}$ & $\begin{array}{l}459 \text { to } 478 \\
722 \text { to } 741 \\
722 \text { to } 741 \text { and } 669 \text { to } 687\end{array}$ & D10599 \\
\hline dMyogenin & $\begin{array}{l}\text { Sense } \\
\text { Antisense } \\
\text { Sense deletion }\end{array}$ & $\begin{array}{l}\text { AGC AGC CTC AAC CAG CAG GA } \\
\text { TCT GCC TGG TCA TCG CTC AG } \\
\text { AGC AGC CTC AAC CAG CAG GAA GCG AGT GCG GCT CTG GCA }\end{array}$ & $\begin{array}{l}432 \text { to } 451 \\
591 \text { to } 610 \\
432 \text { to } 451 \text { and } 507 \text { to } 525\end{array}$ & D90157 \\
\hline${ }^{\mathrm{e}} \beta$-actin & $\begin{array}{l}\text { Sense } \\
\text { Antisense } \\
\text { Antisense deletion }\end{array}$ & $\begin{array}{l}\text { AAT GAG AGG TTC AGG TGC CC } \\
\text { ATC ACA GGG GTG TGG GTG TT } \\
\text { ATC ACA GGG GTG TGG GTG TTG TGG ACA GGG AGG CCA GGA }\end{array}$ & $\begin{array}{l}3140 \text { to } 3159 \\
4190 \text { to } 4209 \\
4190 \text { to } 4209 \text { and } 4081 \text { to } 4099\end{array}$ & X00182 \\
\hline
\end{tabular}

Bases shared by deletion and antisense (or sense) primers are underlined. Primers were designed on the basis of the following sequences: aLin et al. (21), bSaitoh et al. (22), cFujisawa-Sehara et al. (23), dFujisawa-Sehara et al. (24), eKost et al. (25). 
Figure 1. Synthesis of target and competitor cDNA templates. A, Single-strand cDNA of embryos was amplified with specific $S$ and AS primers to produce the target fragment. A second PCR was performed with the $S$ and $D$ primers to produce competitors using the target molecules as template. The D primer comprises 19 bases homologous to an internal region of the target template (indicated by the broken line) in addition to the complete AS primer sequence (underlined). B, Schematic representation of the target and competitor cDNAs. Gray boxes indicate annealing sites for the sense and antisense PCR primers. Hatched boxes show the region deleted in competitors. Except for the deletion, competitors are identical to the corresponding target cDNA. $\mathrm{S}=$ sense primer, $A S=$ antisense primer, $\mathrm{D}=$ deletion primer. structed for the different genes under study is presented in Figure 1B.

After electrophoresis, target and competitor templates were identified by their size, excised from the agarose gel and puri-

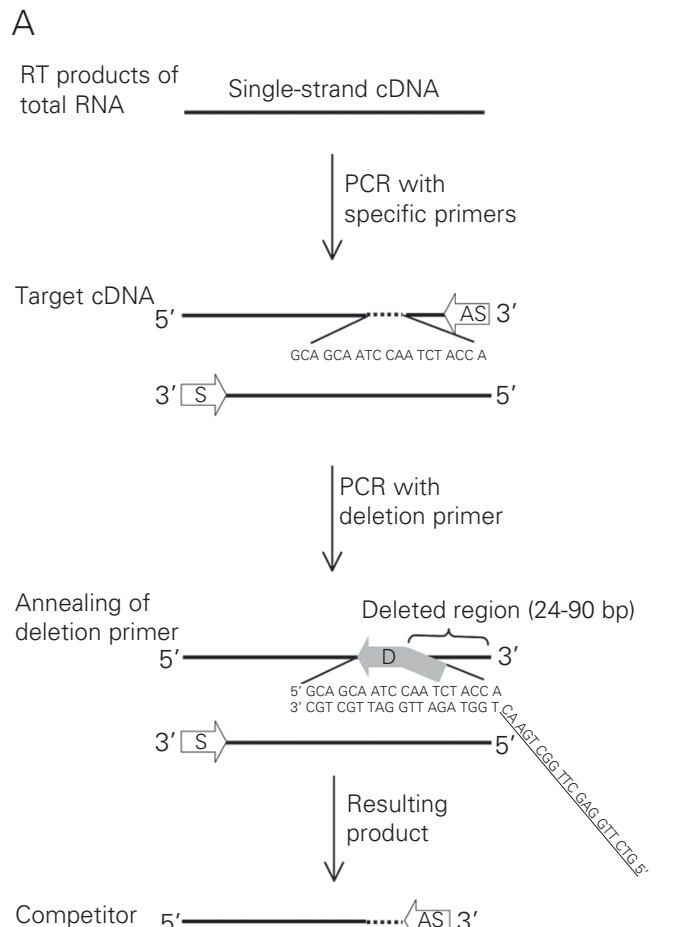

Competitor $\quad 5^{\prime} \longrightarrow$ (AS 3'
cDNA

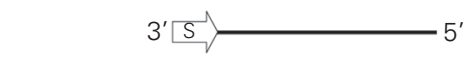

B

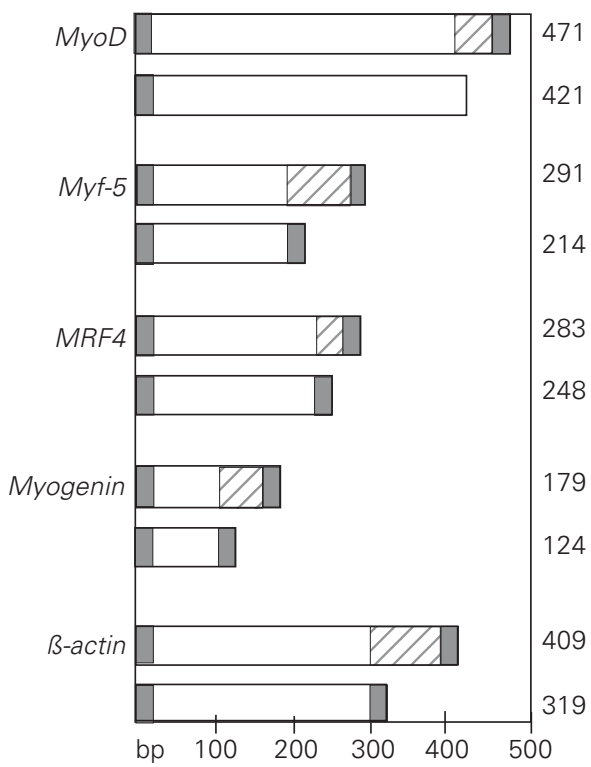

fied with Sephaglas (Pharmacia Biotech, Uppsala, Sweden). Eluted fragments were cloned in pGEM4Z/E. coli JM109 using the SureClone Ligation kit (Pharmacia Biotech). To confirm the identity and the deletion of the desired sequences, clones were sequenced with the BigDye Terminator kit (Applied Biosystems, Foster City, CA, USA) on an ABI PRISM 377 automated DNA sequencer.

\section{Assay sensitivity}

Different quantities of target template (1:10 serial dilutions) were amplified in single reactions to determine the approximate number of molecules that could be detected after 35 PCR cycles. Products were analyzed by electrophoresis on 2-3\% agarose gels. The presence of a band after ethidium bromide staining was the criterion used to determine the lower detection level for each primer pair.

\section{Competitive PCR}

Amplifications were conducted using the sense and antisense primers shown in Table 1. For the $M R F s$, sense primers corresponded to a sequence in exon 1, while antisense primers were complementary to a sequence located in exon 3. Sense and antisense primer sites of $\beta$-actin were in exons 3 and 4 , respectively. All primers were designed to flank an intron to avoid same-size amplification of contaminating genomic DNA.

PCR was performed in a final volume of $25 \mu$ containing $1 \mathrm{X}$ PCR buffer $(10 \mathrm{mM}$ Tris- $\mathrm{HCl}, \mathrm{pH} 8.3,50 \mathrm{mM} \mathrm{KCl}$, and $0.01 \%$ Triton X-100), $1.0 \mathrm{mM} \mathrm{MgCl}_{2}$ (Myf-5, MRF4 and Myogenin) or $1.5 \mathrm{mM} \mathrm{MgCl} \mathrm{M}_{2}(M y o D$, Myogenin and $\beta$-actin), $200 \mu \mathrm{M}$ dNTPs, 5 pmol of each primer, $1.25 \mathrm{U}$ of Taq DNA polymerase (Promega, Madison, CA, USA) and $2 \mu \mathrm{l}$ of cDNA. Sense primers were 5'labelled with fluorescein. A known amount of competitor was directly added to the $1 \mathrm{X}$ PCR master mixture to assure that an equal 
amount was present in all samples to be quantified. The quantity of competitor added to the PCR was determined in preliminary titration experiments performed for each gene. To monitor DNA contamination, negative controls were included in each PCR run.

The first PCR cycle consisted of an initial denaturation at $95^{\circ} \mathrm{C}$ for $3 \mathrm{~min}$, followed by annealing for $1 \mathrm{~min}$ and synthesis at $74^{\circ} \mathrm{C}$ for $1 \mathrm{~min}$. Annealing temperatures for $\beta$-actin/ Myf-5, MyoD/MRF4 and Myogenin were 55 $5^{\circ}$, $57^{\circ}$ and $59^{\circ} \mathrm{C}$, respectively. The subsequent cycles were identical except for a reduction in denaturation time to $1 \mathrm{~min}$ and inclusion of a 10-min extension in the last cycle. These cycle parameters were slightly different from those described by Lin-Jones and Hauschka (26). The total number of cycles was determined for each gene based on amplification kinetic experiments. This assured that quantifications were carried out within the exponential phase of the PCR.

\section{Quantification of PCR products}

Aliquots of amplified products were loaded on $4.25 \%$ denaturing acrylamide gels and submitted to electrophoresis on the Automated Laser Fluorescent DNA sequencer (A.L.F. ${ }^{\mathrm{TM}}$, Pharmacia LKB Biotechnology, Uppsala, Sweden). Following electrophoresis, peaks derived from target and competitor templates were integrated with the Fragment Manager software (Pharmacia LKB Biotechnology).

\section{Construction of standard-curves}

In order to construct standard-curves, known amounts of target and competitor templates were co-amplified in PCR assays prepared as described above (without embryonic cDNA). Serial dilutions of the target cDNA template $(1: 2)$ were performed in water containing $10 \mathrm{ng} / \mu \mathrm{l}$ of plasmidial DNA (with no insert) as carrier. The amount of target cDNA added to each PCR (Ti) varied from $25.6 \times 10^{-\mathrm{r}}$ to $0.1 \times 10^{-\mathrm{r}} \mathrm{fmol}(\mathrm{r}=2,4,5$ or 6) while a fixed amount of $1 \times 10^{-\mathrm{r}} \mathrm{fmol}$ of competitor $(\mathrm{Ci})$ was maintained.

After quantification of PCR products, the logarithm of the ratio between target and competitor peak areas, $\log (\mathrm{T} / \mathrm{C})$, was plotted on the ordinate axis while the logarithm of the amount of target cDNA added to PCR, $\log (\mathrm{Ti})$, was plotted on the abscissa. The equation obtained by linear regression of standard-curves was used to determine the initial number of molecules in embryonic cDNA samples, based on the ratio of target to competitor products in individual PCRs.

\section{Amplification kinetics}

In order to compare the target and competitor amplification kinetics, equivalent amounts of these molecules were co-amplified at increasing cycle numbers. After separation by electrophoresis, the measured peak areas of target and competitor products were expressed as logarithms to produce the corresponding PCR kinetics. These assays allowed the determination of the exponential range of PCR and comparison of the relative amplification efficiencies of target and competitor templates for each gene.

\section{The model}

The mathematical bases of quantitative PCR assays have been discussed by different authors (27-29). The overall accumulation of target and competitor products during PCR can be calculated using the following equations, respectively:

$$
\begin{aligned}
& \mathrm{T}=\mathrm{Ti}\left(1+\mathrm{E}_{\mathrm{T}}\right)^{\mathrm{n}} \\
& \mathrm{C}=\mathrm{Ci}\left(1+\mathrm{E}_{\mathrm{C}}\right)^{\mathrm{n}} \\
& \text { where } \mathrm{T}=\text { amount of target products (after } \\
& \mathrm{PCR}), \mathrm{C}=\text { amount of competitor products, } \\
& \mathrm{Ti}=\text { initial amount of target (added to PCR), } \\
& \mathrm{Ci}=\text { initial amount of competitor, } \mathrm{E}_{\mathrm{T}}=\text { effi- }
\end{aligned}
$$


ciency of target amplification, $\mathrm{E}_{\mathrm{C}}=$ efficiency of competitor amplification, and $\mathrm{n}=$ total number of PCR cycles.

The log-transformed ratio between equations 1 and 2 was:

$\log (\mathrm{T} / \mathrm{C})=\log (\mathrm{Ti} / \mathrm{Ci})+\mathrm{n} \times \log \left(1+\mathrm{E}_{\mathrm{T}}\right) /\left(1+\mathrm{E}_{\mathrm{C}}\right)$

$\mathrm{Y}=\mathrm{ax}+\mathrm{b}$

Thus, Equations 3 and 4 predict that when $\log (\mathrm{T} / \mathrm{C})$ is related to $\log (\mathrm{Ti})$, as done in our assays and in previous descriptions of the method $(30,31)$, standard-curves must produce a straight line with slope $a=1$ and intercept $b=\mathrm{n} \times \log \left(1+\mathrm{E}_{\mathrm{T}}\right) /\left(1+\mathrm{E}_{\mathrm{C}}\right)$. If the amplification efficiencies of the target $\left(\mathrm{E}_{\mathrm{T}}\right)$ and competitor $\left(\mathrm{E}_{\mathrm{C}}\right)$ are identical, the intercept value equals zero; otherwise, it is possible to estimate a value of relative efficiency for competitor (or target) for a fixed number of cycles. In the context of this paper, the term relative amplification efficiency refers to the overall PCR efficiency estimated across the total number of cycles. This calculation was performed assuming $\mathrm{E}_{\mathrm{T}}$ to have the theoretical value 1 and using the expression $E_{C}=\left(2 \times 10^{-b / n}\right)-1$.

\section{Sample normalization}

MRFs and $\beta$-actin mRNA were measured in the same RT reactions to correct for variations due to RNA preparation and RT efficiency. The amount of specific transcripts

Figure 2. Determination of the sensitivity of specific primer pairs. PCR products of reactions containing 1 and $10^{-3}$ to $10^{-7}$ fmol (1:10 serial dilution) of target MyoD after 35 cycles. Bands were visualized on $2 \%$ agarose gels stained with ethidium bromide. The presence of a band established the lowest limit of detection. The number of molecules was calculated using Avogadro's number. in each sample is presented as molecules of
mRNA per $10^{4} \beta$-actin transcripts (e.g., 50 MyoD/10 $\beta$-actin).

\section{Results}

\section{Specificity and sensitivity of competitive RT-PCR}

PCR products of the four MRFs and $\beta$ actin showed the predicted size for target and competitor molecules. The identity of the sequences under study was confirmed by sequencing. Since some of the cloned fragments presented small deletions at the $5^{\prime}$ - or $3^{\prime}$-ends, particular attention was paid to the integrity of these regions. It is very important that target and competitor templates have the same sequences at the priming regions since amplification efficiency is mainly determined by these sequences $(13,30)$. In fact, a single base deletion observed at the annealing site of the forward primer of an $M y o D$ competitor reduced its amplification efficiency by roughly 10-fold in comparison to the target template (data not shown). Thus, templates carrying alterations at the annealing primer sites cannot be used in quantitative assays since most of them will present severe changes in amplification efficiency.

To determine the approximate number of molecules that each specific primer pair was able to amplify, decreasing amounts (1:10 serial dilutions) of target template were amplified in single reactions for 35 cycles (Figure 2). The smallest number of molecules that produced a visible band on agarose gels was considered to be the lowest limit of 
detection for each primer set. $M y o D$ and Myf-5 primers were the most sensitive, being able to detect about 60 molecules per reaction. MRF4 and Myogenin primers displayed intermediate sensitivity, detecting about 600 molecules. Although the Myogenin and MRF4 primers were less sensitive than those of $M y o D$ and $M y f-5$, the sensitivity of the assay was sufficient to detect basal levels of transcription in $\mathrm{HH} 1$ to $\mathrm{HH} 10$ embryos (data not shown), making further optimization unnecessary. $\beta$-actin primers were copied with the lowest sensitivity, and approximately 60,000 molecules were necessary to produce a visible band on agarose gel. However, since the normal content of $\beta$-actin transcripts in cDNA samples was nearly 100 times more than this value, PCR assays did not require additional optimization.

\section{Target and competitor PCR kinetics}

Before constructing standard-curves for the competitive PCR assays, amplification kinetics of target and competitor molecules were compared for each gene under study. This was done in order to determine the exponential range of PCR so that quantification of synthesized products could be performed before the plateau. Thus, the number of PCR cycles used to amplify standardcurve dilutions as well as cDNAs from embryos were established based on kinetic analysis. In addition, the kinetics of the PCR permitted a preliminary comparison of target and competitor amplification efficiency.

The study of $\beta$-actin amplification kinetics produced closely similar results for target and competitor molecules, indicating that both templates were amplified with similar efficiency during the PCR (Figure 3A). An intermediary situation was observed for $M y o D$ and Myogenin whose competitors were slightly more efficient than the target templates (data not shown). The amplification kinetics for target and competitor MRF4 templates were distinct, revealing that these molecules differ in relative efficiency of amplification (Figure 3B). Similar results were obtained for Myf-5 kinetics (data not shown).

\section{Quantification of gene expression}

As the first step to gene expression quantification in embryos, it was necessary to establish the amount of competitor that should be added to the PCR for each gene. Titration experiments were conducted by co-amplifying decreasing amounts of competitor (1:10 serial dilution) with a constant volume $(2 \mu \mathrm{l})$ of embryonic cDNAs. In this way, it was possible to establish for each gene and developmental stage the approximate equivalent point between the endogenous target mRNA and competitor added to the reactions. The equivalent point is identified when bands produced for the target and competitor templates show roughly the same intensity on agarose gel.
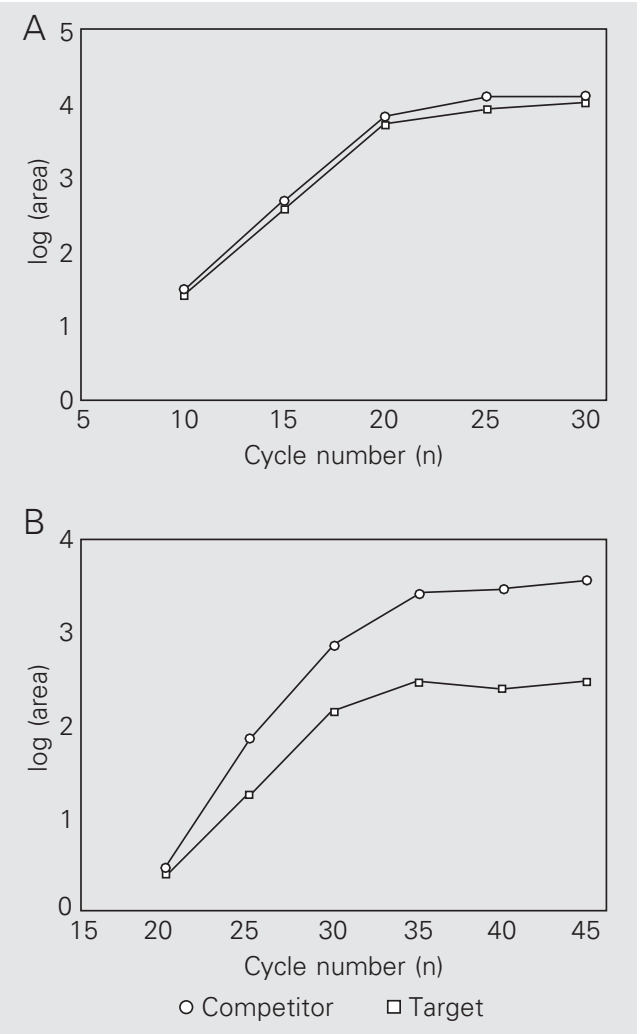

Figure 3. Amplification kinetics of target and competitor cDNAs. $A, B$-actin kinetics showing that, as PCR progresses, the curves of the target and competitor overlap, indicating similar amplification efficiencies. B, MRF4 kinetics revealing that the competitor is amplified more efficiently during PCR than target cDNA. Equal amounts of target and competitor cDNAs were coamplified for increasing numbers of cycles to obtain kinetic data. After quantification of synthesized products, values of peak areas were expressed as logarithm and plotted against the cycle number. Note that PCR products accumulate at a linear rate until the plateau phase is reached. 
A

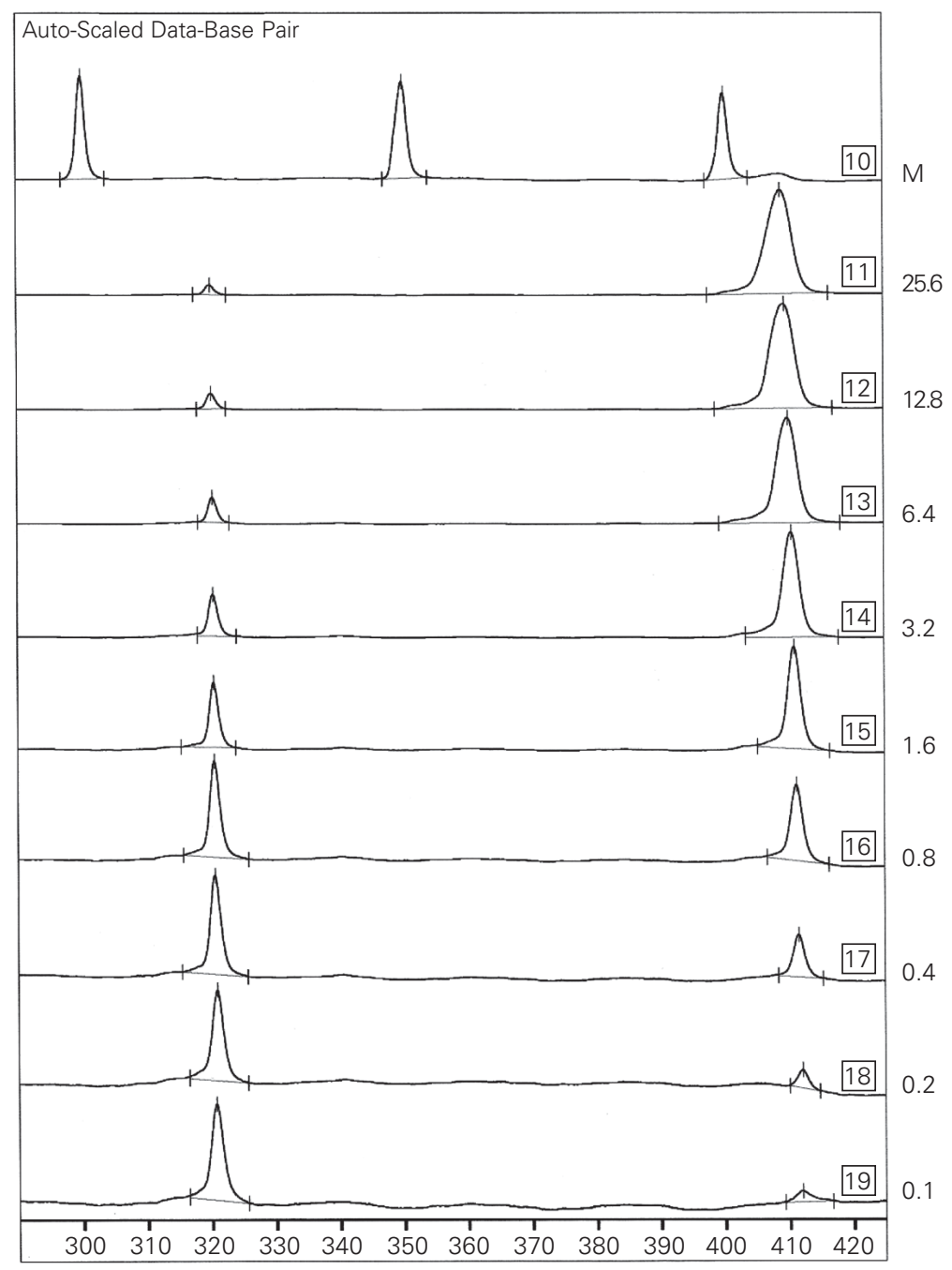

B

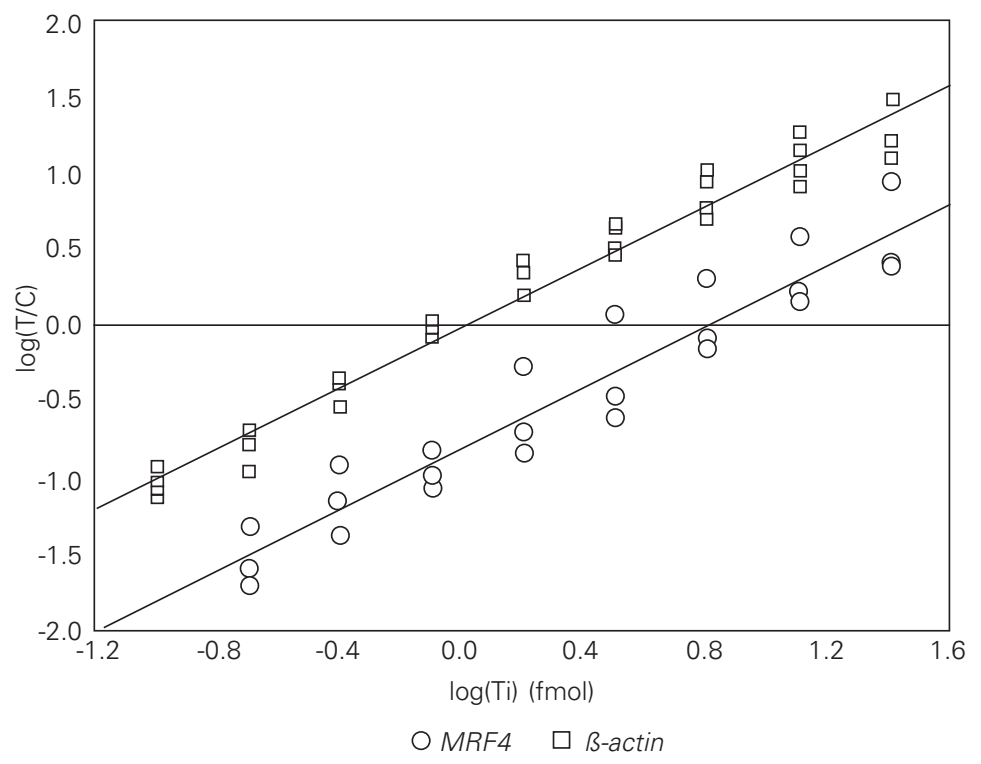

Figure 4. Construction of standard-curves of quantitative RT-PCR assays. A, The B-actin standard-curve peaks after separation on a denaturing acrylamide gel. Note that areas of peaks of the competitor template gradually increased while the peaks of the target decreased. Quantities ranging from 25.6 to $0.1 \times 10^{-2}$ fmol (serial dilution 1:2) of target cDNA were co-amplified with $1 \times 10^{-2} \mathrm{fmol}$ of competitor. Target and competitor templates were labelled with fluorescein. The number of boxes indicates the position of the line. Lane 10 shows the fluorescent 50-bp DNA molecular size marker (M). B, Graphic representation of $\beta$-actin and MRF4 standard-curves. The reactions were prepared at the concentration of $10^{-2}$ and $10^{-6} \mathrm{fmol}$, respectively. PCR products of $\beta$-actin and MRF4 were separated and quantified after 15 and 35 PCR cycles. General linear equations: $Y=0.99 x-0.003$ (B-actin); $Y$ $=1.00 \mathrm{x}-0.805$ (MRF4).

Based on these preliminary titration experiments, standard-curves were prepared at different concentrations. Since the expression levels of MyoD and Myogenin showed wide variation among embryos from different developmental stages, standard-curves were constructed at three concentrations $\left(10^{-6}\right.$, $10^{-5}$ and $10^{-4} \mathrm{fmol}$ ). On the other hand, the expression levels of Myf-5 and MRF4 were always close to $10^{-6} \mathrm{fmol}$ and therefore standard-curves were constructed at this single concentration. Standard-curves for $\beta$-actin were prepared at the concentration of $10^{-2}$ fmol.

To construct the standard-curves, target cDNA was serially diluted (1:2) while the amount of competitor was kept constant in all PCR assays. Amplification products were separated on an automated DNA sequencer that measured the light emitted by the forward fluorescent primer and recorded it as peaks. Since peak areas are proportional to the amount of PCR products and are not related to the size of the amplified fragment, size correction was unnecessary. A typical electropherogram obtained for standardcurves is presented in Figure 4A.

Graphic representation of standard-curves was obtained by plotting the logarithm of the ratio of target to competitor peak areas [ $\log (\mathrm{T} /$ C)] as a function of the amount of target 
Table 2. Comparison of $E_{C}$, slopes and intercepts obtained from standard-curves.

\begin{tabular}{|c|c|c|c|c|c|c|c|c|c|c|c|}
\hline \multirow[t]{2}{*}{ Gene } & \multirow{2}{*}{$\begin{array}{l}\text { Concentration } \\
\text { (fmol) }\end{array}$} & \multirow[t]{2}{*}{$\mathrm{N}$} & \multirow{2}{*}{$\begin{array}{l}\text { Cycle } \\
\text { number }\end{array}$} & \multicolumn{2}{|c|}{ Slope (a) } & \multicolumn{2}{|c|}{ Intercept (b) } & \multicolumn{2}{|c|}{$\mathrm{E}_{\mathrm{C}}\left(\% \mathrm{E}_{\mathrm{T}}\right)$} & \multicolumn{2}{|c|}{$R^{2}$} \\
\hline & & & & From & To & From & To & From & To & From & To \\
\hline \multirow[t]{3}{*}{ MyoD } & $10^{-6}$ & 4 & 35 & 1.06 & 0.91 & -0.32 & 0.12 & 104.3 & 98.4 & 0.96 & 0.99 \\
\hline & $10^{-5}$ & 2 & 30 & 1.08 & 1.02 & 0.00 & 0.14 & 100.0 & 97.9 & 0.97 & 0.99 \\
\hline & $10^{-4}$ & 3 & 25 & 1.09 & 0.98 & -0.33 & 0.05 & 106.1 & 99.0 & 0.99 & 1.00 \\
\hline Myf-5 & $10^{-6}$ & 2 & 35 & 1.04 & 1.03 & -0.79 & -0.48 & 110.7 & 106.5 & 0.98 & 0.99 \\
\hline MRF4 & $10^{-6}$ & 3 & 35 & 1.07 & 0.94 & -0.96 & -0.55 & 113.0 & 107.4 & 0.98 & 0.99 \\
\hline \multirow[t]{3}{*}{ Myogenin } & $10^{-6}$ & 2 & 35 & 0.95 & 0.93 & -0.62 & -0.27 & 108.3 & 103.5 & 0.99 & 1.00 \\
\hline & $10^{-5}$ & 3 & 30 & 1.06 & 0.95 & -0.31 & -0.26 & 104.9 & 104.0 & 0.99 & 0.99 \\
\hline & $10^{-4}$ & 2 & 25 & 1.05 & 1.09 & -0.40 & -0.30 & 107.5 & 105.6 & 0.99 & 0.99 \\
\hline$\beta$-actin & $10^{-2}$ & 4 & 15 & 1.10 & 0.91 & -0.06 & 0.06 & 102.0 & 98.1 & 0.96 & 1.00 \\
\hline
\end{tabular}

The integration of peak areas provided the $\log (\mathrm{T} / \mathrm{C})$ necessary to calculate standard-curve equations. The number of PCR cycles used to amplify serial dilutions of standard-curves as well as cDNAs samples are indicated. At least two independent standard-curves were prepared for each gene. $\mathrm{N}=$ number of independent standard-curves. $\mathrm{E}_{\mathrm{C}}=$ efficiency of competitor amplification; $\mathrm{E}_{\mathrm{T}}$ = efficiency of target amplification; $\mathrm{R}^{2}=$ correlation coefficient.

cDNA initially added to the PCR $[\log (\mathrm{Ti})]$. The equations from which the number of transcripts was calculated were determined by linear regression. As can be observed in Figure 4B, standard-curves form a straight line with slope close to 1 and intercepts varying for different curves. The intercept values of $\beta$-actin standard-curves were always close to zero, indicating that the relative efficiencies of target and competitor templates were equivalent (Figure 4B). In contrast, the intercepts of MRF4 standardcurves showed a clear deviation from zero although the slopes remained close to 1 (Figure 4B). The relative efficiency of all competitors $\left(\mathrm{E}_{\mathrm{C}}\right)$ used in the present study was calculated based on intercept values obtained from standard-curves and assuming a theoretical value equal to 1 for $\mathrm{E}_{\mathrm{T}}$. The $\mathrm{E}_{\mathrm{C}}$ values obtained for MyoD, Myf-5, MRF4 and Myogenin indicate that competitors were usually amplified more efficiently than the corresponding targets (Table 2).

The final step for $M R F$ transcript quantification in embryo cDNAs was the co-amplification of each sample with a known amount of competitor. The gene expression values $[\log (\mathrm{Ti})]$ were obtained by replacing the $\mathrm{Y}$
Table 3. Quantification of MRF transcripts in whole chicken embryos.

\begin{tabular}{rrrrrr}
\hline & \multicolumn{5}{c}{${ }^{*}$ Expression level } \\
\cline { 2 - 6 } & Embryos & MyoD & Myf-5 & MRF4 & Myogenin \\
\hline HH12 & 1 & 1.76 & 0.04 & 0.64 & 0.09 \\
& 2 & 0.72 & 0.14 & 0.91 & 0.02 \\
& 3 & 0.54 & 0.05 & 0.66 & 0.01 \\
& 4 & 0.86 & 0.02 & 0.68 & 0.01 \\
HH18 & 1 & 3.65 & 5.59 & 13.12 & 4.01 \\
& 2 & 2.61 & 3.81 & 7.71 & 3.11 \\
& 3 & 2.13 & 3.73 & 8.42 & 4.19 \\
HH28 & 4 & 7.32 & 2.45 & 4.00 & 3.70 \\
& 1 & 32.34 & 1.32 & 6.51 & 85.96 \\
& 2 & 30.41 & 7.04 & 10.26 & 59.22 \\
& 3 & 33.59 & 7.16 & 8.67 & 84.30 \\
& 4 & 41.67 & 9.45 & 6.16 & 54.76 \\
\hline
\end{tabular}

${ }^{*}$ Results were normalized and reported as molecules of specific transcripts per $10^{4}$ B-actin transcripts.

value of standard-curve equations with the logarithmic ratio of target to competitor peak areas $[\log (\mathrm{T} / \mathrm{C})]$. The level of transcripts for the different MRFs was determined in embryos from stages HH12, HH18 and HH28 (Table 3). All values were normalized for $\beta$ actin content, allowing correction for variations in RNA amount or RT efficiency. 
The intra-assay variability of competitive RT-PCR experiments was evaluated by making replicate measurements of single RNA samples in independent assays (6 to 9 replicates). The coefficient of variation estimated for ß-actin, MyoD/Myogenin and Myf5/MRF4 was roughly 6, 10 and $19 \%$, respectively. The higher level of intra-assay variability observed for Myf-5 and MRF4 was probably related to the low concentration of these transcripts in the cDNA samples analyzed.

\section{Discussion}

In this paper we describe a competitive RT-PCR assay based on the use of standardcurves to quantify $M R F$ transcripts in chicken embryos. Standard-curves consist of a set of reference reactions containing serial dilutions of the target template, which are coamplified with a constant amount of competitor (31). In contrast, for most RT-PCR procedures that require three to five PCR assays for each measurement, the use of standard-curves permits transcript quantification in a single reaction containing known amounts of competitor template. After amplification, the initial number of target molecules in the sample is calculated from the ratio between target and competitor PCR products using linear equations obtained for each gene. Therefore, it is possible to quantify multiple transcripts in a single cDNA sample. Although other investigators have previously reported the use of competitive RT-PCR with standard-curves to quantify gene expression $(30,31)$, the present paper is the first that provides a detailed mathematical description of the method. Furthermore, there is no report of the application of this methodology to the simultaneous quantification of MRFs in cDNAs of single embryos.

Standard-curves are obtained by relating the ratio between the amounts of synthesized products $[\log (\mathrm{T} / \mathrm{C})]$ to the initial amount of target template $[\log (\mathrm{Ti})]$ in the sample. A mathematical description of competitive PCR predicts that such curves must form a straight line defined by $\mathrm{Y}=\mathrm{ax}+\mathrm{b}$. As deduced from Equation 3, another basic assumption to validate standard-curves is a slope value equal to one. Intercept $b$ is defined as $\left[\mathrm{n} \times \log \left(1+\mathrm{E}_{\mathrm{T}}\right) /\right.$ $\left.\left(1+E_{C}\right)\right]$ and thus its value is related to the relative amplification efficiency of target and competitor templates. If the relative amplification efficiency of target to competitor templates is identical, the ratio $\left[\log \left(1+\mathrm{E}_{\mathrm{T}}\right) /(1+\right.$ $\left.E_{C}\right)$ is equal to one and the intercept is equal to zero. On the other hand, if $\mathrm{E}_{\mathrm{C}}$ differs from $\mathrm{E}_{\mathrm{T}}$ there will be a preferential accumulation of one particular PCR product and consequently the intercept value will deviate from zero. This means that equal amounts of competitor and target cDNAs in the sample will not result in products of equal intensity on the gel.

The relative amplification efficiency of the five target templates and the corresponding competitors employed in our quantitative assays was calculated (Table 2). Although the amplification efficiency of target and competitor templates is mainly determined by the anchorage sites for primers (13), the fact that both templates share these sequences does not assure identical amplification rates. In fact, our experience and that of others $(28,32)$ have shown that relative amplification efficiency may differ even when the competitor is closely similar to the target molecule. Since our competitors are smaller than the target templates, it is possible that they have a relatively simpler tertiary structure that could result in a slightly faster denaturation during PCR. This could explain why the amplification efficiency of competitors in most of the genes under study was higher in comparison to those of target templates. Despite this fact, we used these competitors in our competitive RT-PCR assays. This was possible because the $E_{C}$ value is not used to calculate the mRNA copy number. Consequently, equal amplification efficiency for target and competitor is not an 
essential requirement for measurement of gene expression using standard-curves. Obviously, this is an important advantage of the standard-curve method in comparison to more traditional competitive RT-PCR assays that require equal amplification efficiency for target and competitor $(27,28,31)$.

Accurate quantification of mRNAs with standard-curves demands the selection of competitor concentration so that the target to be tested is within the range of values assayed in standard-curves. However, based on $[\log (\mathrm{Ti} / \mathrm{Ci})]$, it can be seen that the concentration range of target and competitor templates does not affect the standard-curve slopes, since the dilution values cancel each other. In our assays we observed that, as expected, the curves constructed for different concentrations (e.g., 10 $10^{-4}, 10^{-5}$ and $10^{-6}$ fmol) were parallel to each other and separated on the $\mathrm{X}$-axis by a distance of 1 (data not shown).

Careful control of the initial amount of RNA as well as RT efficiency is a critical step to assure the correct quantification of transcripts by RT-PCR. In fact, RT is the major source of variation in quantitative assays since the efficiency of this process varies greatly between different samples $(1,3)$. Several studies have reported the use of RNA molecules as competitors to correct samples for variations in RT efficiency (13,33-35). However, the instability of RNA makes it difficult to manage multiple RNA competitors that must be incorporated into single RT reactions in very precise quantities. Thus, we adopted the use of cDNA molecules as competitors in our competitive RT-PCR to simplify the laboratory work and to reduce the chance of erroneous quantifications due to degradation of RNA competitors. Variations in RT efficiency and quantity of total RNA added to the RT reactions were normalized by measuring transcripts of the housekeeping $\beta$-actin gene in the same cDNA samples in which MRFs were quantified.

To measure PCR products we used an automatic sequencer, which allowed target and competitor products to be separated and subsequently quantified with the same equipment. Since target and competitor products were separated from each other on a denaturing gel (as single-strand molecules), the formation of heteroduplexes was not observed despite the structural similarity between competitor and target templates. The formation of heteroduplexes after several cycles of PCR can complicate the interpretation of the competitive RT-PCR results $(8,9)$. As also reported by Cammarota et al. (36), we observed that a higher input of PCR products resulted in underestimation of signals, probably as a consequence of the fluorescent signal being above the capacity of the photodetectors. Thus, it is very important to dilute samples in the presence of overload signals. In fact, we observed that signal overload caused the standard-curves to deviate from the predicted value of 1 , precluding their use in quantitative assays.

Although MRFs are the main regulators of skeletal muscle development, acting on the determination and differentiation of muscle precursor cells, quantitative analyses of their expression are rare (37), probably due to the low level of transcripts and small size of biological samples. In the present paper we presented competitive RT-PCR assays developed for quantification of $M y o D$, Myf-5, Myogenin and MRF4 transcripts in whole chicken embryos. Due to its high sensitivity, competitive RT-PCR was able to measure even the reduced level of $M R F$ transcripts in HH12 chicken embryos. This feature permits studies of embryo tissues of limited size such as somites and specific embryonic muscles. Furthermore, the basal levels of MRFs that are not detectable by other techniques such as Northern blot and ribonuclease protection may be assayed. Besides being sensitive, the method proved to be highly specific and reproducible and allowed quantification of multiple transcripts in single cDNA samples. 


\section{References}

1. Freeman WM, Walker SJ \& Vrana KE (1999). Quantitative RT-PCR: pitfalls and potential. Biotechniques, 26: 112-125.

2. Liu W \& Saint DA (2002). A new quantitative method of real time reverse transcription polymerase chain reaction assay based on simulation of polymerase chain reaction kinetics. Analytical Biochemistry, 302: 52-59.

3. Foley KP, Leonard MW \& Engel JD (1993). Quantification of RNA using the polymerase chain reaction. Trends in Genetics, 9: 380385.

4. Price T, Aitken J \& Simpson ER (1992). Relative expression of aromatase cytochrome P450 in human fetal tissues as determined by competitive polymerase chain reaction amplification. Journal of Clinical Endocrinology and Metabolism, 74: 879-883.

5. Strehlau J, Pavlakis M, Lipman M, Shapiro M, Vasconcellos L, Harmon W \& Strom TB (1997). Quantitative detection of immune activation transcripts as a diagnostic tool in kidney transplantation. Proceedings of the National Academy of Sciences, USA, 94: 695700.

6. Zhang J, Desai M, Ozanne SE, Doherty C, Hales CN \& Byrne CD (1997). Two variants of quantitative reverse transcriptase PCR used to show differential expression of alpha-, beta- and gamma-fibrinogen genes in rat liver lobes. Biochemical Journal, 321: 769-775.

7. Steuerwald N, Cohen J, Herrera RJ \& Brenner CA (1999). Analysis of gene expression in single oocytes and embryos by real-time rapid cycle fluorescence monitored RT-PCR. Molecular Human Reproduction, 5: 1034-1039.

8. Gilliland G, Perrin S, Blanchard K \& Bunn HF (1990). Analysis of cytokine mRNA and DNA: detection and quantification by competitive polymerase chain reaction. Proceedings of the National Academy of Sciences, USA, 87: 2725-2729.

9. Chelly J, Kaplan JC, Maire P, Gautron S \& Kahn A (1988). Transcription of the dystrophin gene in human muscle and non-muscle tissue. Nature, 333: 858-860.

10. Noonan KE, Beck C, Holzmayer TA et al. (1990). Quantitative analysis of MDR1 (multidrug resistance) gene expression in human tumors by polymerase chain reaction. Proceedings of the National Academy of Sciences, USA, 87: 7160-7164.

11. Murphy LD, Herzog CE, Rudick JB, Fojo AT \& Bates SE (1990). Use of the polymerase chain reaction in the quantification of $m d r-1$ gene expression. Biochemistry, 29: 10351-10356.

12. Gaudette MF \& Crain WR (1991). A simple method for quantifying specific mRNAs in small numbers of early mouse embryos. Nucleic Acids Research, 19: 1879-1884.

13. Wang AM, Doyle MV \& Mark DF (1989). Quantification of mRNA by polymerase chain reaction. Proceedings of the National Academy of Sciences, USA, 86: 9717-9721.

14. Becker-Andre M \& Hahlbrock K (1989). Absolute mRNA quantification using the polymerase chain reaction (PCR): A novel approach by a PCR aided transcript titration assay (PATTY). Nucleic Acids Research, 17: 9437-9446.

15. Heid CA, Stevens J, Livak KJ \& Williams PM (1996). Real time quantitative PCR. Genome Research, 6: 986-994

16. Gibson UE, Heid CA \& Williams PM (1996). A novel method for real time quantitative RT-PCR. Genome Research, 6: 995-1001.

17. Arnold HH \& Braun $T$ (2000). Genetics of muscle determination and development. Current Topics in Developmental Biology, 48: 129164.

18. Stockdale FE, Nikovits Jr W \& Christ B (2000). Molecular and cellular biology of avian somite development. Developmental Dy- namics, 219: 304-321.

19. Perry RL \& Rudnick M (2000). Molecular mechanisms regulating myogenic determination and differentiation. Frontiers in Bioscience, 5: D750-D767.

20. Hamburger $V$ \& Hamilton HL (1951). A series of normal stages in the development of the chick embryo. Journal of Morphology, 88: 49-92.

21. Lin ZY, Dechesne CA, Eldridge J \& Paterson BM (1989). An avian muscle factor related to MyoD1 activates muscle-specific promoters in nonmuscle cells of different germ-layer origin and in BrdUtreated myoblasts. Genes and Development, 3: 986-996.

22. Saitoh O, Fujisawa-Sehara A, Nabeshima Y \& Periasamy M (1993). Expression of myogenic factors in denervated chicken breast muscle: isolation of the chicken Myf5 gene. Nucleic Acids Research, 21: 2503-2509.

23. Fujisawa-Sehara A, Nabeshima Y, Komiya T, Uetsuki J, Asakura A \& Nabeshima $Y$ (1992). Differential trans-activation of muscle-specific regulatory elements including the myosin light chain box by chicken MyoD, myogenin, and MRF4. Journal of Biological Chemistry, 267: 10031-10038.

24. Fujisawa-Sehara A, Nabeshima $Y$, Hosoda $Y$, Obinata $T$ \& Nabeshima $Y$ (1990). Myogenin contains two domains conserved among myogenic factors. Journal of Biological Chemistry, 265: 15219-15223.

25. Kost TA, Theodorakis N \& Hughes SH (1983). The nucleotide sequence of the chick cytoplasmic beta-actin gene. Nucleic Acids Research, 11: 8287-8301.

26. Lin-Jones J \& Hauschka S (1996). Myogenic determination factor expression in the developing avian limb bud: an RT-PCR analysis. Developmental Biology, 174: 407-422.

27. Raeymaekers L (1993). Quantitative PCR: theoretical considerations with practical implications. Analytical Biochemistry, 214: 582-585.

28. Connolly AR, Cleland LG \& Kirkham BW (1995). Mathematical considerations of competitive polymerase chain reaction. Journal of Immunological Methods, 187: 201-211.

29. Kotake S, Schumacher Jr HR \& Wilder RL (1996). A simple nested RT-PCR method for quantification of the relative amounts of multiple cytokine mRNAs in small tissue samples. Journal of Immunological Methods, 199: 193-203.

30. Zhao J, Araki N \& Nishimoto SK (1995). Quantification of matrix Gla protein mRNA by competitive polymerase chain reaction using glyceraldehydes-3-phosphate dehydrogenase as an internal control. Gene, 155: 159-165.

31. Tsai SJ \& Wiltbank MC (1996). Quantification of mRNA using competitive RT-PCR with standard-curve methodology. Biotechniques, 21: 862-866.

32. Volkenandt $M$, Dicker AP, Banerjee $D$, Fanin $R$, Schweitzer $B$, Horikoshi T, Danenberg K, Danenberg P \& Bertino JR (1992). Quantification of gene copy number and mRNA using the polymerase chain reaction. Proceedings of the Society for Experimental Biology and Medicine, 200: 1-6.

33. Grassi G, Zentilin L, Tafuro S, Diviacco S, Ventura A, Falaschi A \& Giacca M (1994). A rapid procedure for the quantification of low abundance RNAs by competitive reverse transcription-polymerase chain reaction. Nucleic Acids Research, 22: 4547-4549.

34. Mularoni A, Adessi GL, Arbez-Gindre F, Agnani G \& Nicollier M (1996). Competitive RT-PCR to quantify CFTR mRNA in human endometrium. Clinical Chemistry, 42: 1765-1769.

35. Andersen MR, Farin FM \& Omiecinski CJ (1998). Quantification of 
multiple human cytochrome P450 mRNA molecules using competitive reverse transcriptase-PCR. DNA and Cell Biology, 17: 231-238.

36. Cammarota G, Da Prato L, Nicoletti E, Matteucci D, Bendinelli M \& Pistello M (1996). Quantification of feline immunodeficiency proviruses in doubly infected cats using competitive PCR and a fluores- cence-based RFLP. Journal of Virological Methods, 62: 21-31.

37. Kraus B \& Pette D (1997). Quantification of MyoD, myogenin, MRF4 and Id by reverse-transcriptase polymerase chain reaction in rat muscles - effects of hypothyroidism and chronic low-frequency stimulation. European Journal of Biochemistry, 247: 98-106. 